\title{
A Religiosidade e Espiritualidade de Mulheres com Câncer de Mama Submetidas a
}

\section{Tratamento Cirúrgico}

\author{
Religiosity and Spirituality of Women with Breast Cancer Submitted to Surgical \\ Treatment
}

\author{
Josiane Aparecida Kunz ${ }^{1}$ Carla Regiani Conde ${ }^{2}$ Talita Mayara Rossi Lemos ${ }^{3}$ Ana Elisa de Sousa \\ Barros $^{4 *}$ Maria de Lourdes da Silva Marques Ferreira ${ }^{5}$
}

\section{RESUMO}

O objetivo é compreender a importância da espiritualidade e religiosidade na experiência vivenciada por mulheres com câncer de mama submetidas a tratamento cirúrgico. Utilizou-se abordagem qualitativa e técnica de análise de conteúdo de Bardin. Contou com a participação de 13 mulheres. A coleta dos dados ocorreu por meio da entrevista áudio gravada digitalmente e foi norteada pela questão: como foi, em sua opinião, enfrentar a doença desde o diagnóstico até o tratamento cirúrgico, focando na sua espiritualidade e religiosidade? A análise de conteúdo demonstrou a importância da espiritualidade e religiosidade no enfrentamento e tratamento cirúrgico do câncer e determinou as categorias: "A fé como alicerce", "Prática religiosa", "Doença e morte como determinação de Deus", "Deus como fonte de força e esperança", "Momentos de revolta com Deus", "A cura atribuída por Deus como graça e milagre", "Proximidade com a crença diante do adoecer", "A importância de um olhar holístico da enfermagem". O câncer de mama afeta não só a dimensão física das mulheres, mas os aspectos emocionais, sociais e familiares. Neste sentido, a religiosidade e a espiritualidade foram alternativas buscadas pelas mulheres para enfrentar a doença, enquanto a fé proporcionou a esperança da cura.

Palavras-Chave: Neoplasias da Mama; Religião; Espiritualidade.

\section{ABSTRACT}

Objective: To understand the importance of spirituality and religiosity in the experience of women with breast cancer undergoing surgical treatment. Method: The qualitative approach and the Bardin content analysis technique were used. It counted on the participation of 13 women. The data were collected through the digitally recorded audio interview and was guided by the question: How was it, in your opinion, to face the disease from diagnosis to surgical treatment, focusing on its spirituality and religiosity? Results: Content analysis demonstrated the importance of spirituality and religiosity in the coping and surgical treatment of cancer and determined the categories: Faith as a foundation; Religious practice; Sickness and death as God's determination; God as source of strength and hope; Moments of anger towards God; The healing attributed by God as grace and miracle; Proximity to belief in face of the illness; The importance of a holistic look at nursing. Final Thoughts: Breast cancer affects not only the physical dimension of women, but the emotional aspects, their social and family network. In this sense, religiosity and spirituality were alternatives sought by women to face the disease, while faith provided the hope of healing. Keywords: Breast Neoplasms; Religion; Spirituality.

\footnotetext{
${ }^{1}$ Enfermeira. Graduada pela Faculdade Marechal Rondon/Uninove, São Manuel, São Paulo, Brasil. E-mail: josi_kunz@hotmail.com

2Enfermeira. Doutora em Enfermagem, Faculdade de Medicina de Botucatu, Universidade Estadual Paulista "Júlio de Mesquita Filho" /UNESP, Botucatu, São Paulo, Brasil. E-mail: carlaregiani@yahoo.com.br

${ }^{3}$ Enfermeira. Mestre em Enfermagem, Faculdade de Medicina de Botucatu, Universidade Estadual Paulista "Júlio de Mesquita Filho" /UNESP, Botucatu, São Paulo, Brasil. E-mail: italemos@yahoo.com.br

${ }^{4}$ Enfermeira. Graduada pela Faculdade Marechal Rondon/Uninove, São Manuel, São Paulo, Brasil. E-mail: anaelisa-barros@hotmail.com

${ }^{5}$ Enfermeira. Professora Doutora do Departamento de Enfermagem da FMB/UNESP Faculdade de Medicina de Botucatu, Universidade Estadual Paulista “Júlio de Mesquita Filho"/UNESP, Botucatu, São Paulo, Brasil. E-mail: malusa@fmb.unesp.br
} 


\section{INTRODUÇÃO}

O câncer de mama é o tipo de câncer mais frequente e a principal causa de morte por câncer na população feminina mundial. No Brasil, no ano de 2014, foram confirmados 57.120 casos novos da doença e mesmo existindo métodos preventivos e de rastreamento precoces disponíveis gratuitamente com o objetivo de reduzir os elevados índices de morbidade e mortalidade ocasionados por esta doença, ainda é difícil alcançar números satisfatórios considerando os diversos fatores causais envolvidos. Para o biênio 2016-2017 a taxa de mortalidade ainda permanece elevada e a incidência é de 58 mil novos casos entre as brasileiras ${ }^{(1)}$.

A neoplasia da mama promove experiências emocionais e físicas que duram desde a descoberta do nódulo mamário até a escolha do tratamento. Tal conduta terapêutica pode ser adjuvante, que consiste na quimioterapia, radioterapia e hormonioterapia e/ou cirúrgico, terapia mais eficiente no controle da doença, que refere-se a mastectomia e a cirurgia conservadora $^{(2-3)}$.

O momento do diagnóstico do câncer de mama pode causar um impacto psicológico importante no cotidiano das mulheres, desencadeando inúmeros sentimentos que vão desde estresse, tensão, medo, até a aceitação e motivação para enfrentar as barreiras oriundas do processo da doença ${ }^{(2)}$. Tais sentimentos, portanto, ressaltam a necessidade de um tratamento humanizado e individualizado, abrangendo aspectos físicos, emocionais, sociais e espirituais ${ }^{(4)}$.

Diante deste contexto, religião e espiritualidade podem ser estratégias escolhidas pelas mulheres para enfrentarem e combaterem o estresse causado pela neoplasia ${ }^{(5)}$. A espiritualidade atribui significado a valores, comportamentos e experiências na vida do ser humano, algumas vezes se materializando como práticas religiosas. Existe uma interligação entre a religiosidade, espiritualidade e a saúde, pois historicamente os poderes da cura estavam nas mãos dos que lidavam com o espírito, como por exemplo, sacerdotes, xamã e feiticeiros, sendo estes procurados para tratar dos males do corpo. Relacionava-se tanto a causa como a cura da doença à fatores religiosos. Nos dias de hoje algumas pessoas ainda atribuem a cura de doenças à fé e na crença em Deus ${ }^{(6)}$.

Observa-se que a religiosidade e a espiritualidade proporcionam força e confiança à pacientes com neoplasia para enfrentar as situações difíceis ao longo do processo da busca pela cura, evidenciando assim o uso da fé como necessária nesse percurso da vida. Existem evidências de ligação da fé e das práticas religiosas com o processo de cura da doença ${ }^{(7)}$.

A mama é parte integrante da feminilidade. Desse modo, as mulheres mastectomizadas passam por uma perda de identidade, e nesse aspecto a espiritualidade surge como fator determinante na superação desse trauma. É diante de tal evidencia que se destaca a importância do profissional de saúde em elaborar um plano de cuidado que aborde questões relacionadas à espiritualidade e crenças das mulheres, prestado uma assistência integral à saúde conforme estabelecido no princípio da integralidade do Sistema Único de Saúde ${ }^{(8)}$.

Portanto, acredita ser importante proporcionar à mulher em fase de tratamento de câncer de mama, como o cirúrgico, por exemplo, o apoio espiritual. Neste aspecto, é fundamental conhecer a espiritualidade e religiosidade dessas mulheres, pois pode contribuir para uma assistência de enfermagem mais holística e humanizada. O cuidado da enfermagem compreende a dimensão espiritual e também intervenções, como por exemplo, saber ouvir, estar presente na dor e sofrimento, esclarecer dúvidas sobre a doença, prover esperança e prestar cuidados durante o diagnóstico e tratamento podem ser considerados uma resposta atenciosa à mulher com câncer de mama, além de fortalecer o cuidado espiritual na enfermagem, e valorizam a relação entre a humanização da assistência, espiritualidade/religiosidade e enfrentamento da doença.

Frente ao exposto, surgiu a motivação desta pesquisa na perspectiva de destacar a importância da espiritualidade e religiosidade em mulheres diagnosticadas com câncer de mama e que realizaram cirurgia conservadora, mastectomia total ou parcial. O estudo, portanto, teve como 
objetivo compreender a importância da espiritualidade e religiosidade na experiência vivenciada por mulheres com câncer de mama submetidas a tratamento cirúrgico.

\section{MÉTODO}

Estudo de abordagem qualitativa, que visou compreender o fenômeno de acordo com o ponto de vista do sujeito, caracterizado pela história das relações, representações, crenças, percepções, opiniões e produtos das interpretações que as pessoas fazem a respeito de como vivem, constroem seus artefatos e a si mesmos, sentem e pensam ${ }^{(9)}$.

$O$ estudo foi realizado em uma entidade de assistência social localizada no município de Botucatu, Estado de São Paulo, Brasil, denominada BOTUCCAM (Botucatu no Combate ao Câncer de Mama), oficializada em 08 de novembro de 2002 que tem por missão oportunizar as mulheres e as famílias em situação de vulnerabilidade ou risco social, em decorrência do câncer de mama, o acesso a direitos sociais, melhoria na qualidade de vida e desenvolvimento de sua autonomia. A entidade oferece serviço de atenção à mulher e sua família, convivência social, grupos de convivência semanais onde se realiza acolhimento, trabalhos artesanais, palestras, passeios, lazer e produção artesanal de prótese mamária.

O estudo contou com a participação de 13 mulheres, sendo que destas, nove foram submetidas à mastectomia, três à cirurgia conservadora e uma foi submetida à cirurgia conservadora (quadrantectomia) em uma mama, com posterior mastectomia na outra. Como critérios de inclusão estabeleceu-se que as mulheres apresentassem diagnóstico confirmado de câncer de mama, tivessem sido submetidas à cirurgia conservadora e/ou mastectomia e estivessem inseridas no projeto BOTUCCAM, aceitassem participar da pesquisa e que se sentissem em condições psicológicas para falar sobre os sentimentos vivenciados pelo câncer de mama. Foram excluídas as mulheres que apresentavam déficits cognitivos e que estivessem internadas durante o período de coleta dos dados.

A coleta de dados ocorreu no período de junho a setembro de 2014 e para tanto, utilizou-se um instrumento que abordou aspectos relacionados à caracterização das mulheres e a seguinte questão norteadora: Como foi, em sua opinião, enfrentar a doença desde o diagnóstico até o tratamento cirúrgico, focando na sua espiritualidade e religiosidade?

Ressalta-se que os depoimentos foram áudios gravados digitalmente. As entrevistas cessaram por saturação das informações obtidas, cuja avaliação é feita pelo aspecto de repetição ${ }^{(10)}$.

A análise dos dados referente à questão norteadora foi realizada por meio da proposta de Análise de Conteúdo de Bardin. Esta técnica de investigação trabalha com as palavras e seus significados, procurando conhecer o que está por trás do conteúdo analisado. É constituída pelas seguintes fases ${ }^{(11)}$ : Pré-análise: nesta fase é realizada leitura flutuante, levantamento de hipóteses, objetivos e elaboração de indicadores que fundamentem a interpretação; Exploração do material: os dados são agrupados a partir da observação das entrevistas; Tratamento dos resultados e interpretação: categorizar e classificar elementos semelhantes e, por meio de diferenciação, reagrupar as informações.

Depois de cumpridas essas etapas, foram definidas as categorias pelo agrupamento dos termos relevantes por similaridade de conteúdo. Os sujeitos foram identificados na pesquisa de acordo com nomenclaturas que mantiveram sigilo do nome das mulheres, ou seja, para cada participante foi atribuído um código " $E$ " e posteriormente acompanhados por numero, ou seja, E1, E2 e assim sucessivamente até E13.

$O$ estudo respeitou as exigências formais contidas nas normas nacionais e internacionais regulamentadoras de pesquisas envolvendo seres humanos e foi encaminhado ao Comitê de Ética e Pesquisa da Faculdade de Medicina de Botucatu e aprovado por meio do parecer $n .^{\circ} 670746$ de 02 de junho de 2014.

\section{RESULTADOS}

Para tanto, os resultados foram organizados, apresentados e analisados a partir das respostas às questões da pesquisa, e serão apresentados da seguinte forma: a caracterização 


\section{ARTIGO ORIGINAL}

dos sujeitos: tipo de tratamento cirúrgico, profissão, estado civil, escolaridade, procedência, história familiar de câncer de mama, frequência da realização do autoexame da mama, frequência da realização da mamografia, frequência da realização da consulta ginecológica e realização do exame das mamas pelo profissional de saúde, e categorização qualitativa da análise de conteúdo.

A faixa etária das mulheres entrevistadas neste estudo foi de 34 a 75 anos e os demais dados caracterização estão descritos na Tabela 1.

Tabela 1. Características das mulheres com câncer de mama em relação à importância da religiosidade e espiritualidade, BOTUCCAM, Botucatu, SP, Brasil, 2014.

\begin{tabular}{|c|c|c|}
\hline Caracterização dos sujeitos & Número & Porcentagem (\%) \\
\hline \multicolumn{3}{|l|}{ Tipos de tratamentos cirúrgicos } \\
\hline Mastectomia & 09 & 69,2 \\
\hline Conservadora & 03 & 23,1 \\
\hline Mastectomia e conservadora & 01 & 7,7 \\
\hline \multicolumn{3}{|l|}{ Profissão } \\
\hline Professora & 04 & 30,7 \\
\hline Administradora & 02 & 15,4 \\
\hline Empregada doméstica & 02 & 15,4 \\
\hline Auxiliar de cozinha & 02 & 15,4 \\
\hline Atividades no lar & 02 & 15,4 \\
\hline Aposentada & 01 & 7,7 \\
\hline \multicolumn{3}{|l|}{ Estado civil } \\
\hline Casada & 08 & 61,5 \\
\hline Solteira & 03 & 23,1 \\
\hline Viúva & 02 & 15,4 \\
\hline \multicolumn{3}{|l|}{ Escolaridade } \\
\hline Ensino médio & 05 & 38,4 \\
\hline Ensino fundamental & 03 & 23,1 \\
\hline Superior completo & 03 & 23,1 \\
\hline Pós-graduação & 01 & 7,7 \\
\hline Não alfabetizado & 01 & 7,7 \\
\hline
\end{tabular}




\section{ARTIGO ORIGINAL}

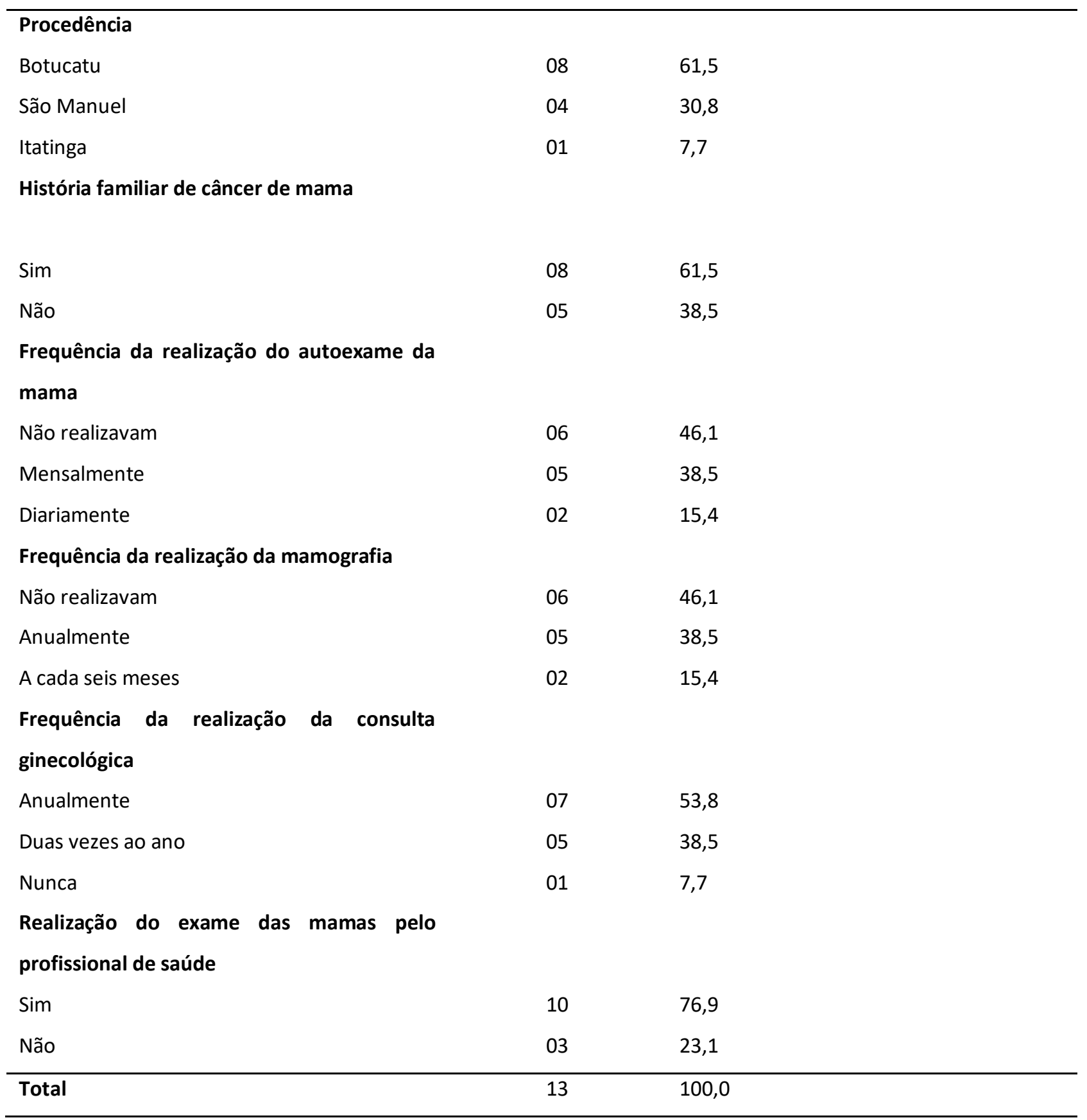

Fonte: dados da pesquisa

Quanto à análise de conteúdo possibilitou compreender a importância da espiritualidade e religiosidade como ideia central no enfrentamento da doença desde o diagnóstico ao tratamento cirúrgico do câncer de mama, identificando as seguintes categorias: A fé como alicerce; Prática religiosa; Doença e morte como determinação de Deus; Deus como fonte de força e esperança; Momentos de revolta com Deus; A cura atribuída a Deus como graça e milagre; Proximidade com a crença diante do adoecer; A importância de um olhar holístico da enfermagem. 
A categoria "A fé como alicerce" emergiu dos depoimentos por diversas vezes as mulheres manifestarem a sua fé e atribuírem a ela toda a esperança pela cura ou até mesmo pelo fato de suportar a doença e suas consequências. Tanto nos momentos de otimismo e coragem, como nos de desesperança e medo. Neste sentido, foi consenso para as participantes que a fé foi a responsável pela cura do câncer.

Eu sou uma pessoa que tem fé [...] eu tenho muita fé em Deus. (E1)

Eu senti que eu tinha que ter muita fé [...] eu tenho muita fé [...] se eu não tivesse fé, eu acho que era muito difícil. (E2)

Quem tem fé Nele vai sempre adiante [...] acho que se eu não tivesse fé e se eu não fosse uma pessoa de fé, talvez eu tivesse me debatido muito [...] mas se você tem fé, o sofrimento, eu te garanto, não dura mais que uma noite [...] dura só uma noite à tristeza de quem tem fé. (E3)

Foi a minha fé em Deus [...] não imaginava que eu tinha tanta fé assim. (E5)

A minha fé dobrou. (E6)

Tenha fé, esperança. (E8)

Sempre com fé em Deus. (E9)

Ajudou bastante a fé. (E10)

Ele nunca desampara e acho que é por aí, tem que ter fé. (E13)

Pode-se observar que as mulheres demonstraram a grande satisfação e bem-estar físico e emocional, conquistados por meio de prática religiosa, como a leitura bíblica, participação em rituais religiosos como cultos e missas, nas orações realizadas por elas, por familiares, membros e líderes religiosos em seu nome, favorecendo o enfrentamento dos momentos difíceis.

As pacientes afirmaram a necessidade de manter suas crenças e comportamentos religiosos antes mesmo da doença. Nos relatos foi possível perceber a relevância que a religiosidade ocupa na vida dessas mulheres.

As crenças e práticas religiosas dessas mulheres possibilitaram a elas recuperar as forças perdidas em cada fase do tratamento, fornecendo um apoio emocional, e devolvendo a expectativa de vida no futuro.

Eu sou católica [...] então vale muito uma religião, uma crença em Deus [...] pode ser a religião que for [...] feliz é aquele que tem uma religião. (E1)

Foi muito bom, o meu pároco [...] ia me visitar, orientava [...] todo mundo, toda semana eles iam à minha casa, faziam oração, então foi muito bom. (E2)

Eu boto meu joelho no chão, eu oro a Deus [...] todo mundo fez oração, oração, oração [...] porque quando eu estou sentindo um vazio eu simplesmente abro a bíblia, leio um salmo [...] eu aconselho todo mundo a conhecer a verdade, a conhecer a palavra, a buscar Deus. (E3)

Eu oro bastante [...] procuro ficar em paz assim. (E4)

Vocês vão ficar rezando para que a mamãe não tenha mais isso em outro lugar. (E7). 
Vou à igreja direto, porque é o meu caminho, entendeu? Que me dá força. (E9)

Eu sou católica e eu não era praticante até então, daí hoje em dia sou praticante, vou à missa toda semana. (E13)

Para algumas mulheres o adoecimento foi interpretado como "Doença e morte como determinação de Deus", sendo que o controle da morte e da vida é uma dádiva que pertencia apenas a Deus. Entregando a Ele o controle da situação, elas deixavam de ser unicamente responsáveis pelo que iria acontecer em suas vidas. Isso torna menos penoso o processo de conformismo sobre o estigma da morte como consequência de uma doença grave.

Deus é muito bom, Ele é justo [...] Eu nunca pedi a Deus assim, me cure, me cure, sabe por quê? Porque tudo que está escrito para mim, quem tem que viver sou eu. (E3)

Eu fui criada assim, não pode fazer tal coisa que Deus não gosta, Deus castiga [...] Não pode deixar o chinelo virado que sua mãe vai morrer [...] Deus é tão perfeito, que Ele já põe lá, as pessoas, sabendo o que vai acontecer [...] eu sou especial para Deus, meu tempo não chegou ainda [...] Seja feita a vontade de Deus [...] Quem manda é Ele. (E7)

Então era porque eu tinha que passar, aí eu me conformei com isso, aceitei, achei que era uma coisa que eu tinha que passar, que eu tinha que passar por isso. (E8)

Deus é quem sabe se tiver que morrer. (E10)

\begin{abstract}
Entregar na mão Dele e se conformar com o resto [...] o futuro a Deus pertence [...] calma, se entrega na mão de Deus e pronto [...] e seja o que Deus quiser. (E11)
\end{abstract}

Eu creio que Deus quer assim. (E12)

A categoria "Deus como fonte de força e esperança" foi desvelada ao evidenciar que algumas mulheres encontraram em Deus a força e o suporte necessário para enfrentar o medo e a angústia. $O$ apoio e a presença da família também foram de extrema importância nesse processo. Nesta perspectiva ao submeter-se às vontades de Deus firmaram com ele uma relação de confiança e companheirismo na busca da cura.

Ele me deu força, coragem e eu enfrentei tudo [...] me animando, me dando coragem e vendo que tem coisas piores $e$ que eu não sou melhor que ninguém. (E1)

Eu falei: eu tenho meu Deus, eu tenho minha família e foi o que levou para cima [...] Eu acho que é o que dá mais força para você. (E2)

Eu confio num Deus superior, no meu Deus que tudo pode. (E3)

Eu fiquei mais assim [...] em paz [...] eu fiquei mais tranquila [...] eu tinha muita confiança de que tudo ia dar certo. (E4)

Olha, por Deus, eu fui embora sem pensar um minuto numa doença [...] Eu falei: Senhor, chega. Eu sempre entreguei minha vida, agora o Senhor vai ter que dar uma força. (E7) 
Eu me levantei praticamente com Deus. (E11)

Eu ouvi Deus me dizer: estou aqui, tenha fé em mim que estou junto com você [...] e está, Cristo está sempre comigo. (E12)

Outra categoria evidenciou "Momentos de revolta com Deus", não ocorrendo uma aceitação imediata da doença. As mulheres após o diagnóstico da neoplasia foram enfrentando e aceitando o processo da doença de forma lenta e gradual, passando de uma condição de negação e revolta para um estado de conformismo e espírito de luta pela sobrevivência, assim para elas a religiosidade e a espiritualidade foram a forma positiva de lidar com a doença e desprender-se da culpa, da sensação de punição e abandono por Deus.

Teve momento que eu fiquei revoltada com Deus [...] eu fiquei muito brava com Ele [...] Por que em mim? Eu nunca tinha feito mal para ninguém [...] nunca matei, nunca roubei [...] se Deus fosse bom ele não tinha me deixado passar por isso [...] fiquei desacreditada um bom tempo [...] mas agora já pedi perdão para ele muitas vezes. (E7)

No começo eu me revoltei. (E8)

A cura atribuída a Deus como graça e milagre foi percebida nos depoimentos, pois algumas mulheres expressam uma total confiança em Deus, concedendo a Ele o mérito pela cura, ainda que se submetesse aos tratamentos convencionais propostos pela equipe de saúde, confiavam ao Ser supremo e possuidor da infinita generosidade a esperança de recuperar a saúde e preservar a vida. Os depoimentos expressaram constantemente sua gratidão a Deus durante as entrevistas.

Deus fez um milagre comigo. (E1)
Eu falo que foi Deus quem me curou, só Ele mesmo [...] graças a Deus foi tudo bem [...] agora eu estou bem, graças a Deus. (E5)

Eu acredito mesmo que foi esse Deus lindo, maravilhoso, que eu tenho dentro de mim, pois mesmo com essa parte da medicina, com a psicologia avançada do jeito que está, se não fosse Deus, eles não teriam conseguido eliminar isso da gente. (E7)

O pior de tudo isso já passou, mas foi bem graças a Deus, passou [...] agradeço a Deus todos os dias porque já faz sete anos. (E8)

Graças a Deus estava no inicio o tumor [...] graças a Deus está estável [...] eu estou conseguindo muitas graças [...] Deus cura. (E9)

Eu rezo: Deus que põe a mão em cima da mão de vocês [profissionais de saúde] e na cabeça também para pensar igual [...] graças a Deus nunca mais tive nada disso [...] não tenho mais essas coisas [...] deixa na mão de Deus porque só ele pode fazer alguma coisa por nós. (E11)

Observou-se que após o adoecimento, algumas mulheres demonstraram Proximidade com a crença diante do adoecer e voltaram-se com mais intensidade para sua religiosidade e espiritualidade, na expectativa de encontrar alívio da dor e do sofrimento, conquistando um conforto emocional por meio de práticas religiosas como frequentar a igreja e fazer orações. 
É Deus, e todas as pessoas que passam por uma coisa ruim, Deus é a primeira coisa. Tem um ditado que Jesus disse: você só me procura quando está chorando, e é a verdade. (E1)

Eu já era, não que eu fui procurar pela dor, eu já era pelo amor, então é mais fácil ainda. (E2)

Eu era católica, mas não era aquela que ia direto à igreja. Agora não, agora vou sempre, então, veio, foi pela dor que eu cheguei, mas estou indo agora. (E5)

Foi pela dor, se não é pelo amor é pela dor [...] eu voltei pela dor mesmo [...] a dor me aproximou da minha igreja [...] eu busquei mais Deus [...] eu era aquela católica não praticante $e$ a partir desse momento eu voltei bem para igreja [...] bem praticante, agora eu sou praticante. (E6)

Nossa, procurei mais a religião. (E9)

Eu sou católica e eu não era praticante até então, daí hoje em dia sou praticante, vou à missa toda semana [...] a religião é muito importante, eu não sei qual é a crença de vocês, mas primeiramente é Deus e a gente só vem descobrir isso depois que você é sacudida. (E13)

A importância de um olhar holístico da enfermagem foi percebida em alguns depoimentos. As mulheres relataram a importância da equipe de enfermagem em reconhecer e compreender suas necessidades emocionais e espirituais, que the proporcionavam conforto e apoio que muitas vezes só é encontrado em Deus. Diante da demanda reprimida de mão de obra, e da procura desenfreada por atualizar teorias e aprimorar técnicas, os enfermeiros abandonavam a comunicação verbal e não verbal com seus pacientes, deixando de perceber essas necessidades e de prestar uma assistência integral. A enfermagem, na visão das mulheres, precisava estar atenta para os gestos, posturas, expressões faciais e orientações do corpo.

Como paciente, as enfermeiras podem ser um Deus para gente. Elas não entendem isso. Elas podem ser um Deus para gente ali, é importante o cuidado por inteiro [...] estão sempre ocupadas e não param para conversar. Senti falta desse da atenção espiritual (E7)

\section{DISCUSSÃO}

O diagnóstico de câncer de mama fez com que as mulheres deste estudo demonstrassem a importância da religiosidade e espiritualidade para aceitar, enfrentar e acreditar que por meio da religião e fé em Deus seria possível a cura da enfermidade.

Corroborando com isso, um estudo mostrou que a fé teve forte influência na recuperação da doença e mesmo em casos sem bons prognósticos clínicos, as mulheres atribuíram sua melhora à fé. Ainda, consideraram que é por meio da fé que aprenderam a valorizar a vida, revisar valores como a importância da família e amigos e a necessidade ter tempo para si mesmo. A religiosidade e espiritualidade foram essenciais para vivenciar o câncer e as transformar em pessoas melhores para o seu próximo e para si mesmo ao investir em uma melhor qualidade de vida, seguindo assim os preceitos de Deus de valorizar seu semelhante assim como a sua própria vida ${ }^{(7)}$.

As mulheres que vivenciam a doença com fé demonstram ser mais fortes, e com tendência a participar ativamente da sociedade, colaborando com a recuperação da sua saúde e de outrem, 
propagando suas experiências e dando exemplos positivos de enfrentamento ${ }^{(12-13)}$.

É por meio da fé que algumas mulheres constroem um significado para a neoplasia da mama e conseguem estabilidade emocional para enfrentar a doença e apresentar esperança de cura. Dessa forma, a religião e espiritualidade são fortalecidas quando as mulheres percebem que a prática diária da oração favorece a aproximação com Deus, minimizando assim os efeitos decorrentes durante o diagnóstico e tratamento do câncer $^{(14)}$.

Ainda, outro estudo evidenciou que mulheres que participam ativamente de liturgias, orações em grupo ou rezam individualmente, seja pela repetição de um mantra, uso de rosário ou conversando abertamente com Deus, apresentam melhoras significativas comparadas àqueles que não praticam nenhum ato religioso ${ }^{(15)}$.

Durante o tratamento e enfrentamento da doença é fundamental o apoio de líderes e membros religiosos por meio de orações, pois proporciona momentos agradáveis do doente com sua comunidade religiosa, criando um ambiente acolhedor e reduzindo assim o estresse vivenciado por estas pacientes. A religiosidade e espiritualidade são responsáveis pela presença de otimismo entre as pacientes oncológicas e quando estas realizam constantemente atividades religiosas, há uma redução expressiva no número de óbitos ${ }^{(4)}$.

No momento em que uma pessoa doente enxerga Deus como ser supremo, o sofrimento torna-se mais suportável, uma vez que o indivíduo deixa de se sentir responsável pela sua doença e morte. Ainda, a espiritualidade é uma forte aliada no caso da mulher evoluir para o óbito, no processo de lutos dos familiares ${ }^{(16)}$.

A ciência lança constantemente para a humanidade inúmeros avanços na área da oncologia, ainda assim nos dias de hoje é comum o paciente oncológico e seus familiares relacionarem a doença a diversos simbolismos negativos como morte, sofrimento, impotência e desesperança. Diante da possibilidade do fim da vida há uma intensa revisão de valores pessoais, mudanças de comportamento e replanejamento pessoal e familiar do futuro ${ }^{(17,18)}$.
Em outros tempos, o câncer era visto como punição divina por uma falta grave cometida pelo indivíduo. Ao passar dos anos, a situação se reverteu e pessoas com doenças graves passaram a perceber a proximidade da morte como uma dádiva para a salvação eterna, proporcionando uma proximidade com Deus e a religião, aceitando a doença como um mal necessário que vem para purificar o espírito. Para resistir ao sofrimento gerado pela experiência da doença, se faz necessário um suporte emocional que vai além do encontrado em tratamentos de saúde convencional. Nesta expectativa, a confiança em Deus vem para suprir essa necessidade, trazendo consigo a esperança da existência de um futuro ${ }^{(17)}$.

Alguns indivíduos em tratamento por câncer são marcados, muitas vezes, por experiências como dor e sofrimento, se deparando com inúmeros fatores desencadeantes de medo e ansiedade, o que faz com que se fragilizem em diversos momentos. No entanto, mesmo nestes momentos de fragilidade, buscam em seu Deus supremo um meio de retomar o controle da situação(16).

Em contrapartida, outras pessoas ao adoecerem podem expressar sentimento de revolta, sendo este marcado por questionamentos sobre o motivo da doença e ter sua fé abalada, tentando culpar Deus por seu adoecimento. Frente a isso, é possível evidenciar que "o sofrimento é enfrentado de maneira diferente em pessoas que vivenciam a religiosidade" e não permitem que a doença seja vista como castigo ou punição divina ${ }^{(7)}$.

Quanto à cura atribuída por Deus como graça e milagre, um estudo identificou que independentemente da religião, a fé e a crença em Deus alimentaram a esperança e foram importantes aliadas na busca da cura que foi tida como um milagre. A sensação de prazer e bemestar é visto como obra do divino, e não das habilidades humanas, pois são sentimentos para sua própria satisfação. Diante da enfermidade, o ser humano se depara com o desconhecido, e na expectativa de alívio do sofrimento ele constrói um contato mais íntimo com a religiosidade $\mathrm{e}$ espiritualidade ${ }^{(19)}$.

A família também é parte importante na tentativa de enfrentamento do câncer uma vez que 
também se apoia na religiosidade e espiritualidade como recurso para vivenciar as situações estressantes que acompanham a doença. Mesmo que não resolva $o$ problema de maneira instantânea, ela é importante aliada na recuperação das forças necessárias no enfrentamento diário da doença ${ }^{(17)}$.

Nos momentos de crise, as pacientes acometidas por neoplasias e seus familiares utilizam a religiosidade e a espiritualidade para enfrentar a doença numa luta constante pela sobrevivência. Isso pode ser entendido como fator relevante no crescimento da sua fé( ${ }^{(16)}$.

Além da família, o profissional de saúde também deve ser outra fonte de apoio à mulher diagnosticada com câncer de mama. Neste contexto, cabe ao enfermeiro, de modo particular, conhecer seu paciente na sua integralidade e ao reconhecer a espiritualidade como forma indispensável para a sua recuperação, ser capaz de propor um planejamento da assistência voltado para necessidade biopsicossocial da mulher desde a descoberta até sua reabilitação da neoplasia mamária ${ }^{(4)}$.

$O$ atendimento de enfermagem requer uma compreensão mais profunda das crenças e valores de seus pacientes, permitindo a este profissional de saúde atender melhor suas necessidades. Durante a formação na área da saúde o aluno recebe conhecimentos objetivos resultando em profissionais carentes de embasamento teórico-prático para abordar questões religiosas e espirituais. Nessa perspectiva ele encontra dificuldades de prestar uma assistência da forma integral, haja vista que se faz necessário considerar a dimensão espiritual para abordar a esperança e o enfrentamento da doença no planejamento, compreendendo o paciente na sua totalidade ${ }^{(20)}$.

Um estudo demostrou que a maioria dos alunos e docentes de enfermagem compreende que a espiritualidade tem uma boa influência na saúde de pacientes oncológicos, mas que a enfermagem não está preparada para abordar esse aspecto durante sua atuação profissional. Corroborando com este estudo, outra literatura identificou fragilidade e despreparo do profissional de enfermagem no âmbito espiritual ao atender pacientes com câncer. Tais profissionais relataram sentimento de desconforto durante a assistência e responsabilizaram a falta de abordagem sobre a temática durante a formação acadêmica. Assim, pode-se concluir que é de grande importância discutir o domínio espiritual durante a graduação, sendo o preparo do enfermeiro fundamental para sanar fragilidades no atendimento integral a mulher com câncer de mama ${ }^{(21)}$. No entanto, mesmo esta temática não sendo discutida profundamente durante a graduação em enfermagem, o apoio espiritual prestado pelo enfermeiro tem estreita relação com a vivência prática do profissional, permitindo que a espiritualidade e religiosidade façam parte do planejamento da assistência de enfermagem ao prescrever cuidados pensando nos aspectos emocionais e espirituais da mulher com câncer de mama.

\section{CONCLUSÃO}

O câncer de mama afeta não só a dimensão física das mulheres, mas principalmente seus aspectos emocionais, abalando sua rede social e familiar. Considerada uma doença inesperada, muitas vezes traz sentimentos como medo da perda do ente querido e repercussões sociais como a mobilização de amigos e vizinhos no oferecimento de apoio financeiro e emocional.

Os resultados evidenciaram que a religiosidade e espiritualidade são partes relevantes na vida das mulheres que participaram deste estudo, e foram alternativas buscadas por elas para enfrentar a doença. Neste sentido, a fé representou uma poderosa aliada capaz de proporcionar a esperança da cura.

A maioria mantinha uma ligação com alguma instituição religiosa e ressaltaram que o mais importante era Deus na sua infinita bondade e amor. Ficou evidente que Deus foi o maior responsável pela força adquirida para o enfrentamento da doença e pela almejada e solicitada cura.

Percebe-se também que a cura não foi uma imposição para persistirem na crença e na fé, uma vez que ao vivenciarem a doença e conhecendo sua gravidade, as mulheres entregaram a decisão de 
viver ou morrer a Deus, aceitando a doença e suas consequências.

Em uma pequena parte dos depoimentos constatou-se o abalo temporário da fé durante a fase inicial da doença, gerando questionamentos sobre os significados de sofrimento, vida e morte resultando na sensação de vazio que posteriormente foi preenchido por meio da reconciliação com Deus.

Em alguns relatos, também se constatou o retorno à religiosidade, diante do medo após receber o diagnóstico de câncer, necessitando de uma força superior, força que elas procuraram e encontraram em Deus. Mesmo diante da cura, essa comunhão com Deus continuou fulgente e cada vez mais alicerçada na fé e no amor.

Os resultados do estudo apresentam limitações por não permitir generalizações à outra população, próprio do número de participantes da pesquisa qualitativa. Entretanto, trouxe reflexão sobre a espiritualidade e religiosidade das mulheres diagnosticadas com câncer de mama e acompanhadas no BOTUCCAM. Assim, outros estudos com novas abordagens metodológicas, podem colaborar para explorar as repercussões espirituais e religiosas de mulheres com câncer mama.

Por fim, este estudo apontou a importância de um cuidado de enfermagem mais amplo ao paciente oncológico, avaliando os aspectos físicos, emocionais, sociais e espirituais. Para prestar uma assistência de qualidade, é necessário formar profissionais com envolvimento, sensibilidade, atenção, compreensão, diálogo, apoio, conforto e esclarecimento de dúvidas.

\section{Agradecimento}

A Maria Paula Soares Pozati (in memorian) pela participação na concepção, planejamento, análise e interpretação dados e que nos deixou durante a finalização deste estudo.

\section{REFERÊNCIAS}

1. Instituto Nacional de Câncer José Alencar Gomes da Silva (BR). Coordenação de Prevenção e Vigilância. Estimativa 2016: incidência de câncer no Brasil [Internet]. Rio de Janeiro: INCA; 2015 [acesso em 7 Jul 2017]. Disponível em: http://www.inca.gov.br/estimativa/2016/estimativ a-2016-v11.pdf.

2. Menezes NN, Schulz VL, Peres RS. Breast cancer diagnosis' psychological impact: a study since patients' reports in a support group. Estud. Psicol. [internet] 2012; 17(2):233-40. [Access 10 march 2018]; Available in: http://www.scielo.br/scielo.php?script=sci_arttext \&pid=S1413-

$294 X 2012000200006 \& \operatorname{lng}=e n \& n r m=i s o$.

3. Souza SR, Voeux PL. Brunner \& Suddarth: Manual de enfermagem médico-cirúrgica. 13. ed. Rio de Janeiro: Guanabara Koogan; 2015.

4. Furlan MCR, Bernardi J, Vieira AM, Santos MCC, Marcon SS. Percepção de mulheres submetidas à mastectomia sobre o apoio social. Cienc Cuid Saúde [Internet]. 2012 [acesso em 10 mar 2018]; 11(1):66-73. Disponível em: http://www.periodicos.uem.br/ojs/index.php/Cien cCuidSaude/article/view/18860/pdf.

5. Silva AV, Zandonade E, Amorim MHC. Anxiety and coping in women with breast cancer in chemotherapy. Rev. Latino-Am. Enfermagem. 2017; 25:e2891. [Access 16 july 2017]; Disponível em: http://www.scielo.br/pdf/rlae/v25/pt_0104-1169rlae-25-e2891.pdf.

6. Conselho Regional de Psicologia de São Paulo. $\mathrm{Na}$ Fronteira da Psicologia com os Saberes Tradicionais: Práticas e Técnicas. Volume 2. São Paulo: CRP-SP; 2016.

7. Geronasso $\mathrm{MCH}$, Coelho D. A influência da religiosidade/espiritualidade na qualidade de vida das pessoas com câncer. Saúde Meio Ambient [Internet]. 2012 [acesso em 10 mar 2018]; 1(1):173-87. Disponível em: http://www.periodicos.unc.br/index.php/sma/artic le/view/227/270.

8. Oliveira GR, Neto JF, Salvi MC, Camargo SM, Evangelista JL, Espinha DCM, Lucchetti G. Saúde, espiritualidade e ética: a percepção dos pacientes e a integralidade do cuidado. Rev Bras Clín Med. 
[online] 2013 [acesso em 10 mar 2018]; 11(2):140-

4. Disponível

em: http://files.bvs.br/upload/S/1679-

1010/2013/v11n2/a3566.pdf.

9. Minayo MCS. O desafio do conhecimento: pesquisa qualitativa em saúde. 13. ed. São Paulo: HUCITEC- ABRASCO; 2014.

10.Thiry-Cherques HR. Saturação em pesquisa qualitativa: Estimativa empírica de dimensionamento. Revista PMK [Intenet]. 2009 [acesso em 10 mar 2018]; 3(4):20-7. Disponível em: http://www.revistapmkt.com.br/Portals/9/Edicoes /Revista_PMKT_003_02.pdf.

11.Bardin L. Análise de conteúdo. Lisboa (PT): Edições 70; 2010.

12.Cavalcante MLF, Chaves F, Ayala ALM. Câncer de mama: sentimentos e percepções das mulheres mastectomizadas. Rev. Aten. Saúde [Intenet]. 2016 [acesso 10 mar 2018]; 14(49):41-52. Disponível em: http://seer.uscs.edu.br/index.php/revista_ciencias _saude/article/view/3736.

13.Fonseca AA, de Souza ACF, Rios BRM, Bauman $C D$, Piris AP. Percepções e enfrentamentos de mulheres com câncer de mama: do diagnóstico ao tratamento. Revista Eletrônica Acervo Saúde [Internet]. 2017 [acesso em 17 jul 2017]; (Suppl 5):222-9. Disponível em: http://acervosaud.dominiotemporario.com/doc/S9_2017.pdf.

14.Veit CM, Castro EK. Coping religioso/espiritual positivo em mulheres com câncer de mama: um estudo qualitativo. Psicol [Internet]. 2013 [acesso em 11 mar 2018]; 44(3):331-41. Disponível em: http://revistaseletronicas.pucrs.br/ojs/index.php/r evistapsico/article/viewFile/15820/10408.

15.Carvão RCB. Oração e Meditação: Duas Práticas no Enfrentamento de Doenças [monografia]. Campinas: CESBLU - Centro Educacional de Blumenau ALUBRAT - Associação Brasileira de Transpessoal; 2009.
16.Sampaio $A D$, Siqueira $\mathrm{HCH}$. Influência da Espiritualidade no Tratamento do Usuário Oncológico: Olhar da Enfermagem. Ensaios e Ciência: C. Biológicas, Agrárias e da Saúde [Intenet]. 2016 [acesso em 11 mar 2018]; 20(3):153-60. Disponível em: http://www.pgsskroton.com.br/seer/index.php/en saioeciencia/article/view/4433/3473.

17.Ferreira MDLSM, Dupas G. Repercussão do diagnóstico do câncer de mama no contexto familiar. Rev. Bras. Pesq. Saúde [Internet]. 2017 [acesso em 10 mar 2018]; 18(4):84-92. Disponível em:

http://periodicos.ufes.br/RBPS/article/view/16735 /11566.

18. De Brito DTF, Agra G, Medeiros MVD, Pereira IKC, Macedo EDL, de Andrade FLM. Sentimentos de Enermeiras no Cuidado de Pessoas com Feridas Neoplásicas. Ver Enf Atual [Internet]. 2018 [acesso em 15 mar 2019]; 86(24):1-11. Disponível em: http://revistaenfermagematual.com/arquivos/ED_ 86_REVISTA_24/03.pdf.

19.Sanchez CP. Enfrentamento do câncer: apoio a pacientes em tratamento. Revista Ensaios Teológicos [Internet]. 2017 [acesso em $10 \mathrm{mar}$ 2018]; 2(2):126-45. Disponível em: http://ead.batistapioneira.edu.br/ojs/index.php/en saios/article/view/156/190.

20.Penha RM, Silva MJP. Do sensível ao inteligível: novos rumos comunicacionais em saúde por meio do estudo da Teoria Quântica. Rev Esc Enferm USP [Internet]. 2009 [acesso em 10 mar 2018]; 43(1):208-14. Disponível em: http://www.scielo.br/scielo.php?script=sci_arttext \&pid=S0080-62342009000100027\&lng=en.

21.Espinha DCM, de Camargo SM, Silva SPZ, Pavelqueires S, Lucchetti G. Opinião dos estudantes de enfermagem sobre saúde, espiritualidade e religiosidade. Rev. Gaúcha Enferm [Internet]. 2013 [acesso em 10 mar 2018]; 34(4):98-106. Disponível em:

http://www.scielo.br/scielo.php?script=sci_arttext \&pid=S1983-14472013000400013\&Ing=en. 
